\title{
About the Oscillatory Flow Phenomenon within 3D Cylindrical Annulus: Critical Buoyancy and Annulus' Aspect Ratio for Oscillation Stability
}

\author{
Karim Ragui ${ }^{1, *}$, Rachid Bennacer ${ }^{2}$, Abdelkader Boutra ${ }^{1}$ \\ ${ }^{1}$ Process \& Mechanical Engineering Department, USTHB University, Algeria. \\ ${ }^{2}$ LMT-ENS Cachan, Paris Saclay University, France. \\ Email: ragui-karim@live.fr
}

\begin{abstract}
The main purpose of our investigation is to provide the impact of some pertinent parameters, as the thermal buoyancy and the geometry ratio, on the oscillatory flow' stability of a Newtonian fluid which occurs within an annulus, found between a cold outer circular cylinder and a hot inner one, to come out at the end with critical conditions that could predict this phenomenon into such an industrial geometry. To do so, a physical model is developed using the Lattice-Boltzmann approach side by side with the finite difference one. The validity of the latter is ascertained after comparison between our primary predictions and various experimental \& theoretical ones. By using an unsteady-state regime, both Isotherms and velocity profiles of our convective fluid are widely inspected. Going far with its value, the use of a critical aspect ratio could dieout the impact of any investigated parameter on the oscillatory flow. Then, only a conductive regime will take control into the annulus. It is to note that a three dimensions D3Q19 model was adopted based on a cubical Lattice.
\end{abstract}

\section{Nomenclature}

a Coefficient in external forces $(=g \beta)$

$\mathrm{a}_{\mathrm{ij}} \quad$ Coefficients in equation (6)

c Cold section

$\mathrm{c}_{\mathrm{s}} \quad$ Sound velocity in the Lattice $\left(\mathrm{c}_{\mathrm{s}}=1 / \sqrt{3}\right)$

$\mathrm{C}_{\mathrm{p}} \quad$ Specific heat at constant pressure, $\left[\mathrm{J} \mathrm{kg}^{-1} \mathrm{~K}^{-1}\right]$

f Pure fluid

$\mathrm{f}_{\mathrm{eq}} \quad$ Equilibrium distribution function

$\mathrm{F}_{\text {ext }} \quad$ External force

$\mathrm{f}_{\mathrm{i}} \quad$ Distribution function

h Hot section

$\mathrm{k}$ Thermal conductivity, [W $\mathrm{W}^{-1} \mathrm{~K}^{-1}$ ]

$\mathrm{H}_{\mathrm{x}, \mathrm{y}, \mathrm{z}} \quad$ Enclosure dimensions, [m]

$\mathrm{m}_{\mathrm{j}} \quad$ Moments

$\mathrm{Nu} \quad$ Mean Nusselt number

Pr Prandtl number $(\operatorname{Pr}=v / \alpha)$

$\mathrm{S}_{\mathrm{j}} \quad$ Relaxation rate

$\mathrm{t} \quad$ History time, [s].

$\mathrm{T}$ Temperature, [K].

$\mathrm{Ra}_{\mathrm{T}} \quad$ Thermal Rayleigh value, $\left(=2 T_{0} H^{3} a / v k\right)$

$\mathrm{u} \quad$ Horizontal velocity component, [m]

$\mathrm{v} \quad$ Vertical velocity component, [m] w Depth velocity component, [m]

$\mathrm{x}, \mathrm{y}, \mathrm{z}$ Dimensional Cartesian coordinates, [m]

$\mathrm{X}, \mathrm{Y}, \mathrm{Z}$ Dimensionless coordinates, $(x / H, y / H, z / H)$

$\alpha \quad$ Thermal diffusivity, $\left[\mathrm{m}^{2} \mathrm{~s}^{-1}\right]$

$\beta \quad$ Thermal expansion coefficient, $\left[\mathrm{K}^{-1}\right]$

$\theta \quad$ Dimensionless temperature

$\omega_{\mathrm{i}} \quad$ Coefficients of the equilibrium function

$\rho \quad$ Density, $\left[\mathrm{kg} \mathrm{m}^{-3}\right]$

$\varepsilon \quad$ Energy square

$v \quad$ Kinematic viscosity, $\left[\mathrm{m}^{2} \mathrm{~s}^{-1}\right]$

$\Omega \quad$ Collision Operator

\section{Introduction}

Convective flows of horizontal annulus, which bounded by two circular cylinders and held at different temperatures, have been intensely studied through the last decades, as well experimentally as numerically [1-7]. Such a research investment was mainly related to its importance and it wide range of industrial applications, much like heat exchangers, solar power collectors, and nuclear reactor core' stability, to name but a few [1-8]. 
It is established that the basic flow with small thermal buoyancies (i.e. $R a_{T}$ ) consists of two large cells, symmetrically located with respect to the vertical plane that contains the cylinder axis [9-12]. By increasing the Rayleigh value (simply said, the pure thermal buoyancy effect), this flow becomes unstable and leads to a very complicated phenomenon, so-called Oscillation, according to the value of the aspect ratio $\mathrm{D}_{\mathrm{i}} / \mathrm{D}_{\mathrm{o}}[13-17]$.

Regarding such a phenomena, various experimental and numerical studies were developed. The complexity was to find the main correlation that could relate the impact of both the thermal buoyancy and the annulus' aspect ratio on the oscillation flow-stability.

Contradictions in the descriptions of these flows, and the global correlation, prompted a study directed at obtaining more detailed information concerning the onset and characteristics of this oscillatory flow. The present investigation is undertaken to extend the Rayleigh number range with the critical aspect ratio of the annulus, in conjunction with this extension of range, to obtain precise information about the characteristics of such a flow phenomenon. For better understanding of such complex phenomenon, a Three-dimensional investigation will be reported through these pages.

\section{Statement of interest}

The investigated configuration, shown through Fig.1, consists of a three dimensional annulus found between a cold outer circular cylinder and a hot inner one, which are coaxially mounted.
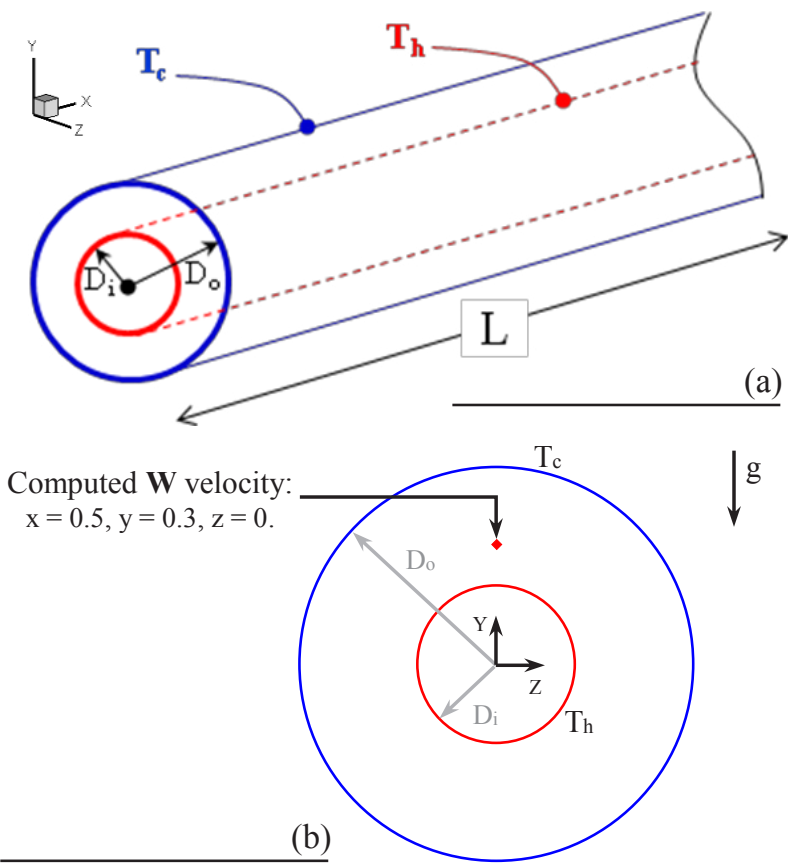

Fig.1: Simulation domain with its boundary conditions.
The fluid, which filled such a space, is assumed to be Newtonian. Its thermo-physical properties are presumed to be constant except the density variation, in the buoyancy term, which depends linearly to the local temperature value (i.e. Boussinesq approximation) [18].

\section{Computational Setup}

\subsection{Problem Formulation}

As a numerical investigation, the dimensionless conservation equations, describing the transport phenomenon within the annulus could be developed as follows:

$\nabla \overrightarrow{\mathrm{V}}^{\prime}=0$

$\frac{\partial \overrightarrow{\mathbf{V}}^{\prime}}{\partial \mathrm{t}}+\left(\overrightarrow{\mathrm{V}}^{\prime} . \vec{\nabla}\right) \overrightarrow{\mathrm{V}}^{\prime}=-\vec{\nabla} \mathrm{P}+\operatorname{Pr} \nabla^{2} \overrightarrow{\mathrm{V}}^{\prime}+\operatorname{Ra} \operatorname{Pr} \theta$

$\frac{\partial \theta}{\partial \mathrm{t}}+\left(\overrightarrow{\mathrm{V}}^{\prime} \cdot \vec{\nabla}\right) \theta=\nabla^{2} \theta$

where $\mathrm{V}^{\prime}$ is the velocity component; $\mathrm{U}$ in $\mathrm{X}$ direction, $\mathrm{V}$ in $\mathrm{Y}$ direction and $\mathrm{W}$ in the $\mathrm{Z}$ one. $\mathrm{Ra}(=\mathrm{g} \beta \Delta \mathrm{T}$ $\left.\mathrm{H}^{3} / \alpha v\right)$ is the thermal Rayleigh number, when $\operatorname{Pr}(=v / \alpha)$ is the Prandtl one.

\subsection{Lattice Boltzmann Approach}

Regarding the Lattice Boltzmann approach for the Newtonian fluids, a nineteen-velocity model on a threedimensional lattice, noted as D3Q19, is adopted [19]. For the dynamic model, two successive phases are taken into account, as the particles' propagation from nodes to their neighbors, and the collision phase, where these particles on the same Lattice redistribute and relax into their quasiequilibrium. Subsequently, the particles distribution equation could be expressed as follows [19-20]:

$$
\frac{\partial \overrightarrow{\mathrm{f}}}{\partial \mathrm{t}}+\overrightarrow{\mathrm{c}} \nabla \overrightarrow{\mathrm{f}}=\left(\frac{\partial \overrightarrow{\mathrm{f}}}{\partial \mathrm{t}}\right)_{\text {scat }}
$$

where $f(x, c, t)$ is the distribution function depending on the particle velocity (c) at a location ( $\mathrm{x}$ ) and a time ( $\mathrm{t}$ ).

According to Guo et al. [20], the right side term of this particles distribution equation displays the diffusion process when the new equilibrium distribution is rebuilt after the collision.

As a function of the location $(x)$ and the time $(t)$, the fluid's shape could be defined as particles populations vector, noted as $\mathrm{f}_{\mathrm{i}}$, (where $i$ is taken between 0 to 18). Thus, the discrete distribution equation can be given as:

$$
\mathrm{f}_{\mathrm{i}}\left(\mathrm{x}+\mathrm{c}_{\mathrm{i}} \Delta \mathrm{t}, \mathrm{t}+\Delta \mathrm{t}\right)=\mathrm{f}_{\mathrm{i}}(\mathrm{x}, \mathrm{t})+(\Omega \mathrm{f})_{\mathrm{i}}
$$

where $\left(f_{i}\right)$ is the space vector based on the discrete velocity set. $\Omega$ is the collision operator. 
It is to note that a primary discrete velocity sets will be created, then, from the set of 18 vectors pointing from the origin to the above neighbors and the source vector $(0,0,0)$.

The space vector $\left(\mathrm{f}_{\mathrm{i}}\right)$ will be constructed using the moment of the last. The relationship between two spaces is defined by means of the below equation (Eq.6), when the coefficient $\mathrm{a}_{\mathrm{ij}}$ is calculated using the particle velocity $\mathrm{c}_{\mathrm{i}}$ [19-20].

$$
\mathrm{m}_{\mathrm{j}}=\sum_{\mathrm{i}} \mathrm{a}_{\mathrm{ij}} \mathrm{f}_{\mathrm{i}}
$$

The corresponding 19 moments $\mathrm{m}_{\mathrm{j}}$ are the mass density $\left(m_{0}=\rho\right)$, the kinetic energy independent of the density $\left(\mathrm{m}_{1}=\mathrm{e}\right)$, the kinetic energy square independent of the density and kinetic energy $\left(\mathrm{m}_{2}=\varepsilon=\mathrm{e}^{2}\right)$, the momentums $\left(\mathrm{m}_{3 ; 5 ; 7}=\mathrm{j}_{\mathrm{x} ; \mathrm{y} ; \mathrm{z}}\right)$, the energy flux independent of the mass flux $\left(\mathrm{m}_{6 ; 8 ; 10}=\mathrm{q}_{\mathrm{x} ; \mathrm{y} ; \mathrm{z}}\right)$, and the symmetric traceless viscous stress tensor $\quad\left(m_{9}=3 p_{x x}, m_{11}=p_{w w}=p_{y y}-p_{z z}\right.$, with $p_{x x}+p_{y y}+$ $\left.\mathrm{p}_{\mathrm{zz}}=0, \mathrm{~m}_{13 ; 4 ; 15}=\mathrm{p}_{\mathrm{xy} ; \mathrm{yz} ; \mathrm{zx}}\right)$.

The two vectors of quadratic order, $\mathrm{m}_{10}$ and $\mathrm{m}_{12}$, have the same symmetry as the diagonal part of the traceless tensor $\mathrm{p}_{\mathrm{ij}}$, while the other three vectors of the cubic order are parts of a third rank $\mathrm{m}_{16 ; 17 ; 18}$ tensor, with the symmetry of $\mathrm{j}_{\mathrm{k}} \mathrm{p}_{\mathrm{nm}}$. The diagonal collision matrix $\mathrm{S}_{\mathrm{ij}}$ is given as follows:

$\mathrm{S}_{\mathrm{ij}}=\left(\begin{array}{l}0, \mathrm{~s}_{1}, \mathrm{~s}_{2}, 0, \mathrm{~s}_{4}, 0, \mathrm{~s}_{4}, 0, \mathrm{~s}_{4}, \mathrm{~s}_{9}, \mathrm{~s}_{10}, \\ \mathrm{~s}_{9}, \mathrm{~s}_{10}, \mathrm{~s}_{13}, \mathrm{~s}_{13}, \mathrm{~s}_{13}, \mathrm{~s}_{16}, \mathrm{~s}_{16}, \mathrm{~s}_{16}\end{array}\right)$

It is worth to denote that relaxations are related to the dynamic viscosity [21].

About the energy equation, and because of the nonexistence of non-linearity, the finite-difference scheme is found more required than the LBE-Scheme. The relation between the temperature and the flow fields is found to be as far as the force in the y-direction, which arises with the temperature gradient, is introduced. The latter is, then, used in the y-velocity calculations as shown in the advection term of the energy equation which cited below:

$$
\frac{\partial \mathrm{T}}{\partial \mathrm{t}}+\overrightarrow{\mathrm{V}} \nabla \mathrm{T}=\mathrm{k} \Delta \mathrm{T}
$$

Even thought that the mean transfer rate of our system is not presented within these pages, it is important to denote that the latter can be computed on each $\mathrm{X}$ position using the following expression [11-12]:

$$
\left.\mathrm{Nu}\right|_{\mathrm{X}}=\frac{1}{\mathrm{~A}} \int_{0}^{\mathrm{A}}(\partial \theta / \partial \mathrm{n}) \mathrm{dS}
$$

where $\mathrm{n}$ is the normal direction with respect to the inner or the outer surface and $\mathrm{A}$ is the surface area of each cylinder.

\section{Results \& Discussion}

Our presented results are generated for various dimensionless groups, such as the Thermal Rayleigh values $\left(10^{3} \leq \mathrm{Ra} \leq 10^{6}\right)$ and the annulus' aspect ratios $(0.10$ $\left.\leq \mathrm{D}_{\mathrm{i}} / \mathrm{D}_{\mathrm{o}} \leq 0.84\right)$. The Prandtl number is fixed at 6.2. The predicted hydrodynamic and thermal fields' variables are presented through the Streamlines and the Isotherm plots.

The performance of the using code versus 3D convection problems is established by comparing predictions with other numerical results, namely those of Fusegi et al. [22] and Frederick et al. [23]. By taking into account the same hypotheses, Table.1 demonstrates the evolution of the mean thermal coefficient which computed into an Air-cube. As we can see, the present results and those of Fusegi et $a l$. and Frederick et $a l$. are found to be in excellent agreement, with a maximum discrepancy of about $1.81 \%$.

Table 1: Average Nusselt number obtained with our computer code and those of references [22, 23], $\operatorname{Pr}=0.71$.

\begin{tabular}{ccccc}
\hline & $\begin{array}{c}\text { Fusegi } \\
\text { et } \text { al. }[22]\end{array}$ & $\begin{array}{c}\text { Frederick } \\
\text { et } \text { al. }[23]\end{array}$ & $\begin{array}{c}\text { Present } \\
\text { Prediction }\end{array}$ & $|\Delta \%|_{\max }$ \\
\hline $10^{3}$ & 1.085 & 1.071 & 1.071 & 1.29 \\
$10^{4}$ & 2.100 & 2.057 & 2.062 & 1.81 \\
$10^{5}$ & 4.361 & 4.353 & 4.367 & 0.32 \\
$10^{6}$ & 8.770 & 8.740 & 8.761 & 0.24 \\
\hline
\end{tabular}

To ascertain the numerical code validity with a natural convection phenomenon into the horizontal cylindrical annulus, those obtained experimentally by Bishop et al. [24] have been taken into consideration. Fig. 2 provides the comparison between the previous experimental data of Bishop et $a l$. and the present predictions.
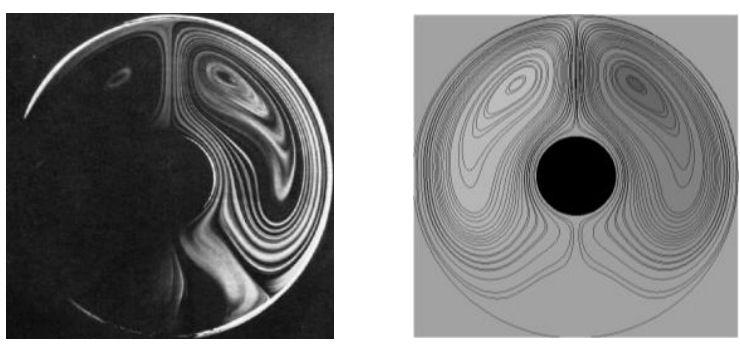

$\left(\mathrm{D}_{\mathrm{i}} / \mathrm{D}_{\mathrm{o}}=0.24\right)$
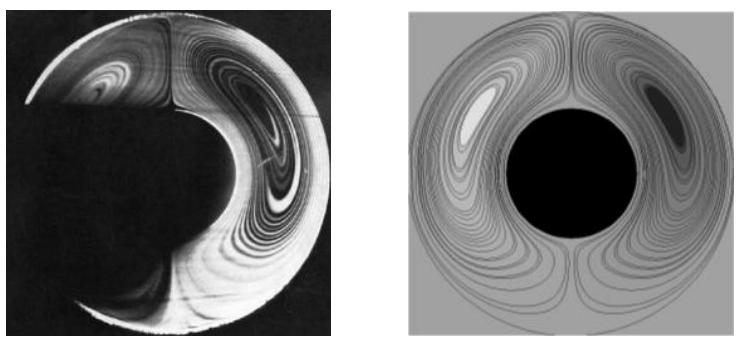

$\left(\mathrm{D}_{\mathrm{i}} / \mathrm{D}_{\mathrm{o}}=0.40\right)$

Bishop et al. [24]

Present predictions 
Fig.2: Experimental streamlines validation.

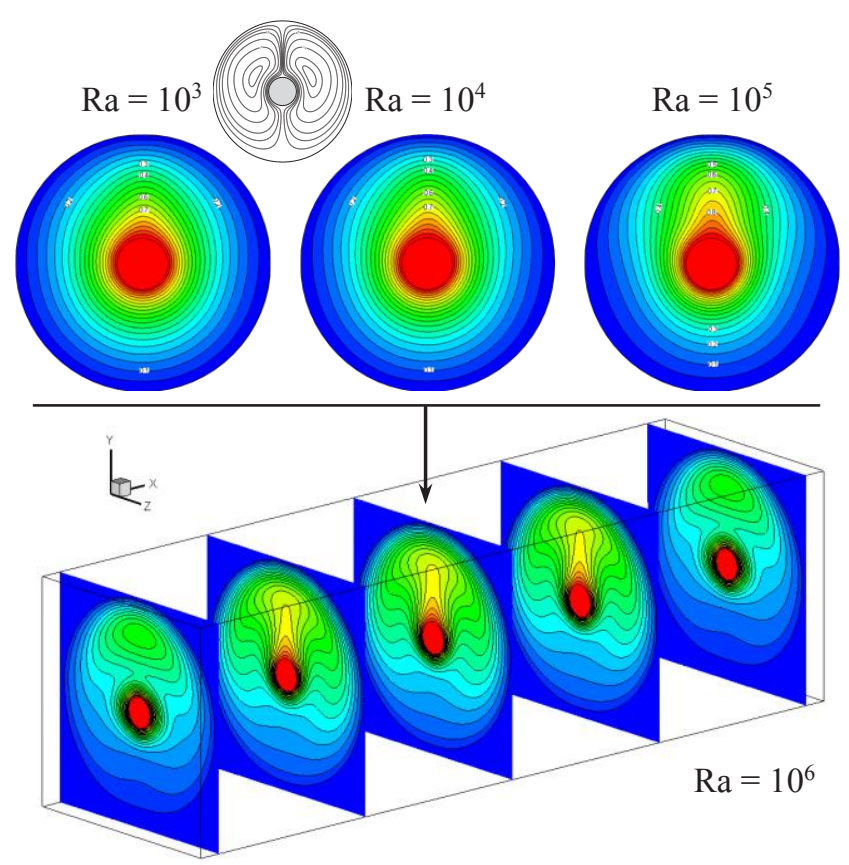

Fig.3: 3D Visualization of the streamlines and the Isotherm plots at various thermal buoyancies, $\operatorname{Pr}=6.2, \mathrm{D}_{\mathrm{i}} / \mathrm{D}_{\mathrm{o}}=0.24$.

Once again, the numerical results exhibit a great qualitative concordance with the experimental ones, what support the use of our code to investigate a convective phenomenon into such geometries.

Beginning our investigation by taking a fixed annulus aspect ratio $\left(D_{i} / D_{0}\right)$ of about 0.24 , which is good enough to get an oscillatory flow phenomena within the annulus $[24,25]$. Subsequently, Fig.3 displays a series of Streamlines and Isotherm plots, according to various values of the thermal Rayleigh number, much like $10^{3}$ to $10^{6}$.

For these patterns, two symmetrical counter-rotating cells are formed within the annulus space. The fluid flows up along the inner-cylinder surface and down along the outer-cylinder surface, at a relatively high speed with increasing Rayleigh value (i.e. the thermal buoyancy).

The Isotherm plots represented for low Rayleigh numbers, (i.e. $\mathrm{Ra}=10^{3}$ and $\mathrm{Ra}=10^{4}$ ), are found to be nearly the same, and barely changed, demonstrating a dominated-conduction transfer regime, unlike the Iso-plots of high Rayleigh values, (i.e. $\mathrm{Ra}=10^{5}$ and $\mathrm{Ra}=10^{6}$ ), where the latter becomes more distorted.

In other words, a thermal boundary layer is shaped all along the cylinders' surfaces and becomes thinner with high Rayleigh values. Additionally to this, a thermal plume appears at the top portion of the inner cylinder (as for the case of $10^{6}$ ) which may indicate the domination of the convection mechanism within the annulus.

In fact, what we presented into the previous figure (i.e. Fig.3) is only a fixed image of the developed history-time solution (at $\mathrm{t}=300)$ when the oscillatory phenomenon has not started yet. Going far with this history-time (i.e. $\mathrm{t}$ ), Fig. 4 comes-out to clear-up the plots developed within the annulus as a function of oscillation time. As we can see, and for a high thermal buoyancy of about $10^{6}$ and a length (L) of about 3.5 times the outlet diameter $\left(D_{0}\right)$, the flow complication is clearly observed.

An oscillatory flow starts to light out after an oscillation time $\mathrm{t}=300$ (see for instance $\mathrm{t}=2000$ and 2500). The $\mathrm{W}$ velocity-profiles, which displayed in Fig.5 at a specific position within the annulus $(\mathrm{X}=0.5, \mathrm{Y}=0.3$ and $\mathrm{Z}=0$.) and presented with various Rayleigh values, proved that under a critical thermal buoyancy (i.e. Ra value), the Newtonian fluid still developed as a stable regime (i.e. no oscillatory flow is denoted). Such a critical limit links to a Rayleigh value of about $1.9910^{5}$.

Yes of course, this critical Rayleigh value still related to the fixed aspect ratio, what make us wondering about the impact of the latter (i.e. the annulus aspect ratio), by changing the buoyancy impacts (by changing the Rayleigh value).

To make this point clear enough, we developed (as a sample) the $\mathrm{W}$ velocity profile's evolution with various aspect ratios, by using a fixed Rayleigh value $\left(\mathrm{Ra}=10^{6}\right)$ as plotted Fig.6. As we can see, using an aspect ratio higher than $24 \%$ makes the oscillatory flow phenomenon instable. With a critical value, such a phenomenon dies-out to make the Newtonian-fluid flow as a stable regime. The critical value in denoted at an aspect ratio of about $64 \%$.

These promoting results make us searching for a global relation which may summarize the critical conditions for the oscillation stability. Unfortunately, this part cannot be presented through this paper reason to the page limitation.

\section{Conclusion}

Oscillatory flow's conditions within a concentric cylindrical annulus were described and investigated with some pertinent parameters, much like the thermal buoyancy and the annulus' aspect-ratio. By taking into account a large range of these latter, the oscillatory flow within such a complex geometry, consequent to the imposed temperature gradient, can be controlled by a coupled effect of these pertinent parameters.

Summarizing other predictions, which could not be presented within this paper reason to the page limitation, allowed us to predict the global relation between these critical conditions (i.e. critical $\mathrm{Ra}_{\mathrm{T}}$ and $\mathrm{D}_{\mathrm{i}} / \mathrm{D}_{\mathrm{o}}$ ) and the oscillation stability. This presented part might provide particularly useful in verifying any instability analysis; which might be put forth in the future.

The oscillatory flow within a porous annulus will be the next step, in order to complete such an investigated part and to make general our descriptions of such an industrial problem and geometry. 


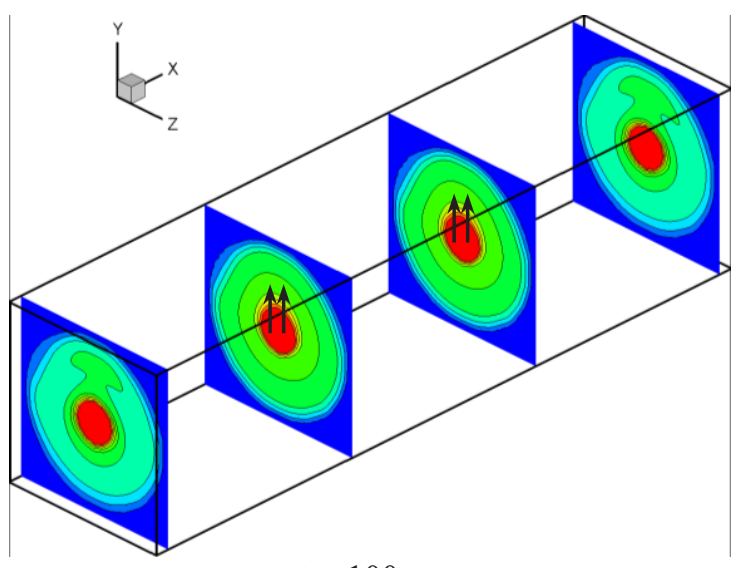

$\mathrm{t}=100$

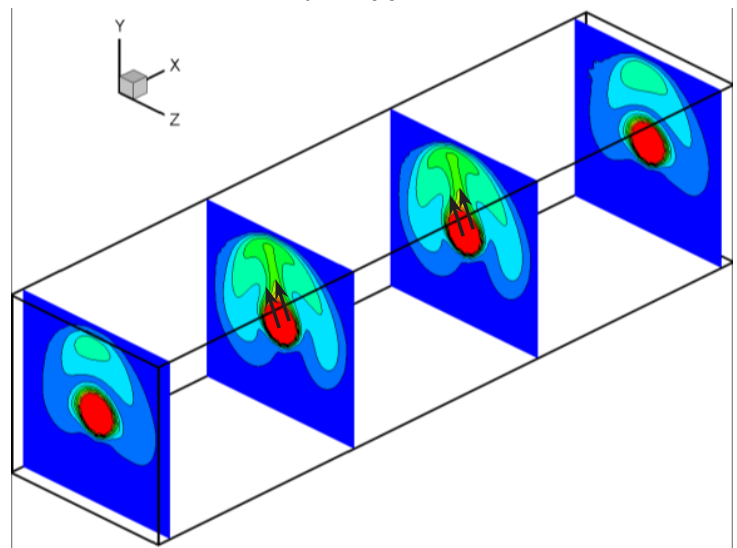

$\mathrm{t}=2000$

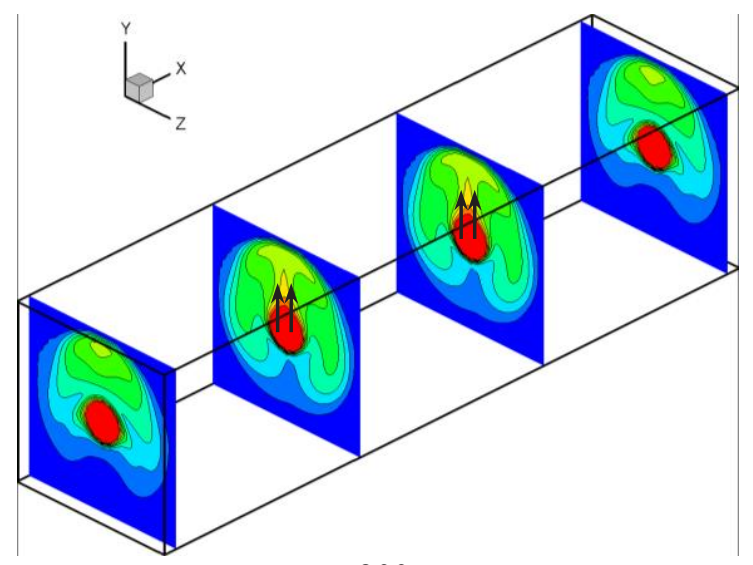

$t=300$

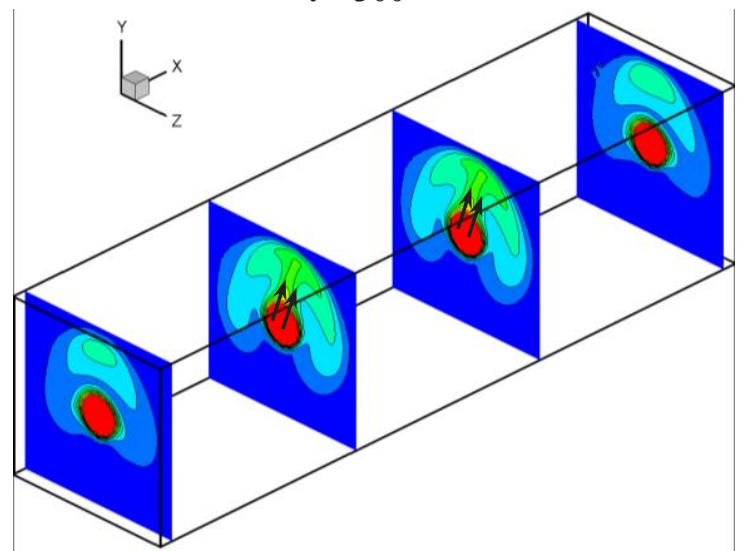

$\mathrm{t}=2500$

Fig.4: Isotherm plots as a function of oscillation time. $\mathrm{L}=3.5 \mathrm{D}_{\mathrm{o}}, \mathrm{Ra}=10^{6}, \operatorname{Pr}=6.2, \mathrm{D}_{\mathrm{i}} / \mathrm{D}_{\mathrm{o}}=0.24$.

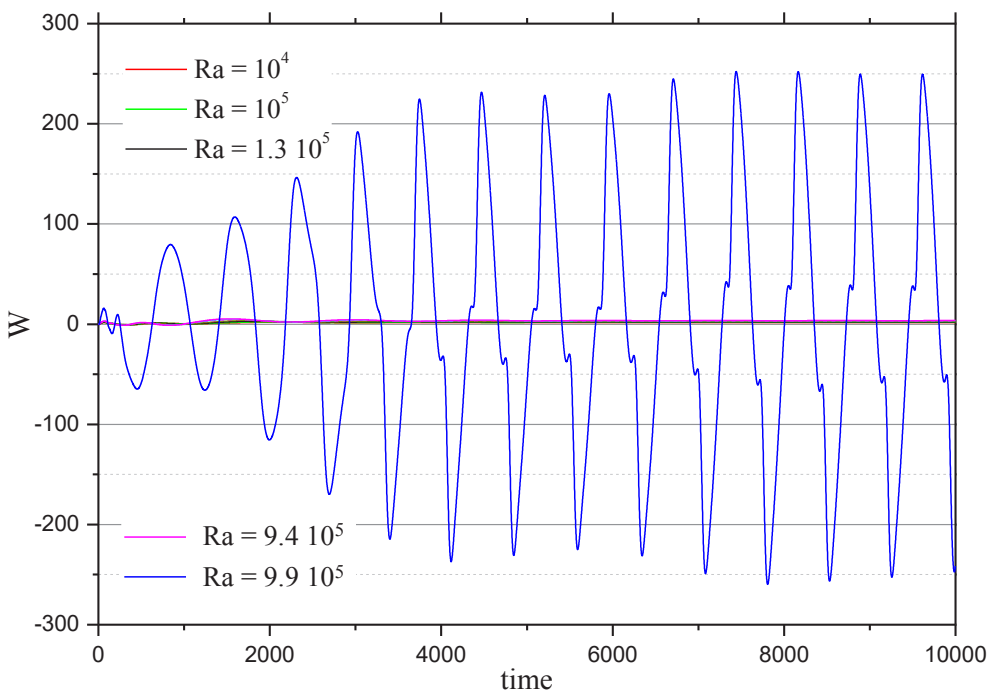

Fig.5: $\mathrm{W}$ velocity profiles as a function of Rayleigh values. $\mathrm{D}_{\mathrm{i}} / \mathrm{D}_{\mathrm{o}}=0.24, \operatorname{Pr}=6.2$. 

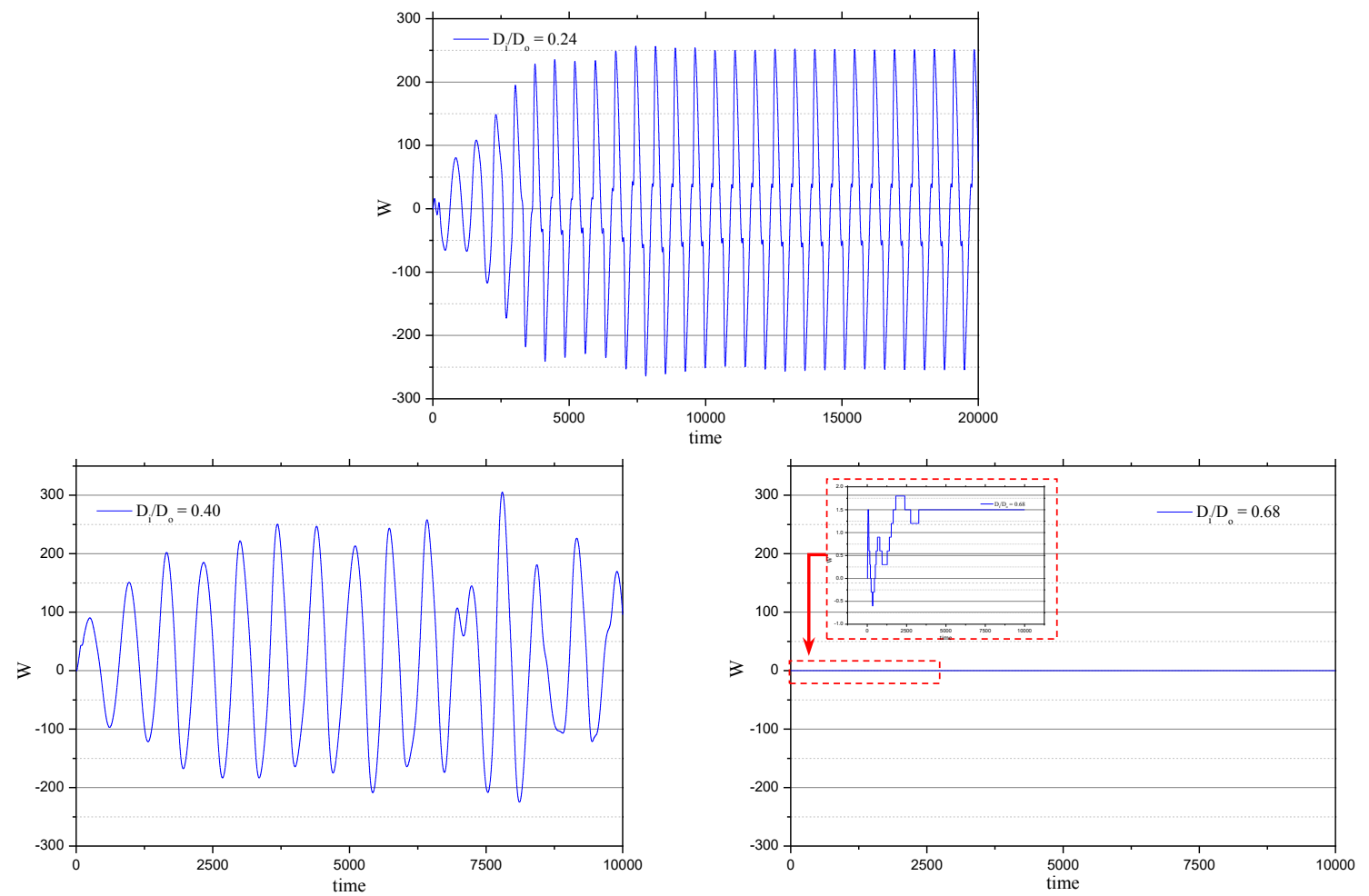

Fig.6: W velocity profiles as a function of the oscillatory time, for various aspect ratios, $\operatorname{Ra}=10^{6}, \operatorname{Pr}=6.2$.

\section{Acknowledgments}

We are very thankful to the Department of Mechanical and Technology at Paris Saclay University and Prof. R. BENNACER for his time and consideration.

\section{References}

1. J.P. Caltagirone, J. Fluid Mech. 76:337-362 (1976).

2. K. Himasekhar, H.H. Bau, J. Fluid Mech., 187: 267300 (1988).

3. P. Teertstra, M.M. Yovanovich, $7^{\text {th }}$ AIAA/ASME Joint Therm. Heat Transfer Conf., Albuquerque, NM, June 15-18, HTM: 357-402 (1998).

4. J.P.B. Mota, I.A.A.C. Esteves, C.A.M. Portugal, J.M.S.S. Esperanca, E. Saatdjian, Int. J. Heat Mass Transfer, 43: 4367-4379 (2000).

5. M. Ait Saada, S. Chikh, A. Campo, Int. J. Heat Fluid Flow, 28: 483-495 (2007).

6. I.A. Badruddin, A. Abdullah-Al-Rashed, N.J. Salman Ahmed, S. Kamangar, Int. J. Heat Mass Transfer, 55: 2184-2192 (2012).

7. N.J. Salman Ahmed, I.A. Badruddin, K. Jeevan, Z.A. Zainal, K.S. Nazim Ahamed, Int. J. Heat Mass Transfer, 54: 3822-3825 (2011).

8. K. Ragui, A. Boutra, Y.K. Benkahla, R. Bennacer, Int. J. Heat and Technology, 36(2): 761-772 (2018).

9. P. Giuseppe, C. Eric, L. Guy, Physics of fluids, 18: 104-107 (2014).
10. K. Ragui, A. Boutra, R. Bennacer, Y.K. Benkahla, Applied Mechanics, Behavior of Materials, and Engineering Systems, Book Lect.Notes Mechanical Engineering, Springer, (2016).

11. K. Ragui, A. Boutra, R. Bennacer, Y.K. Benkahla, Int. J. Heat Mass Transfer, 126: $72-94$ (2018).

12. K. Ragui, A. Boutra, R. Bennacer, Y.K. Benkahla, J. Heat and Mass Transfer, 01: 01-18 (2018).

13. E.H. Bishop, C.T. Carkey, R.E. Powes, Inf. J. Heat Mass Transfer, 11: 1741-1752 (1968).

14. G. Labonia, G. Gui, J. Fluid Mech., 375: 179-202 (1998).

15. O. Yuichi, T. Gaku, H. Makoto, Heat Transfer-Asian Research, 35: (1) (2006).

16. D. Veronika, P. Denis, Shock and Vibration, 2016: 816, (2016).

17. K. Ragui, Y.K. Benkahla, R. Bennacer, Heat Conduction: Methods, Applications and Research, Book, Nova Science Publishers, (2019).

18. A. Bejan, John Wiley \& Sons, Inc., Hoboken, New jersey, USA (2004).

19. D. d'Humières, B.D. Shizgal and D.P. Weaver, Editors, AIAA Progress in astronautics and aeronautics, 159: 450-458 (1992).

20. Y. Guo, R. Bennacer, S. Shen, D.E. Ameziani, M. Bouzidi, Int. J. Num. Methods Heat Fluid Flow, 3: 227-248 (2010). 
21. K. Fallah, M. Khayat, M.H. Borghei, A. Ghaderi, E. Fattahi, J. Non-Newt. Fluid Mech, 177: 01-14 (2012).

22. T. Fusegi, J.M. Hyun, K. Kuwahara, B. Farouk, Int. J. Heat Mass Transfer, 34: 1543-1557 (1991).

23. R.L. Frederick, S.G. Moraga, Int. J. Heat Fluid Flow, 28: 289-298 (2007).
24. E.H. Bishop, C.T. Carleyt and R.E. Powe, Int. J. Heat Mass Transf., 11: 1741-1752 (1968).

25. K. Himasekhar, H.H. Bau, J. Fluid Mech., 187: 267300 (1988). 